\title{
All Women Belong in the Kitchen, and Other Dangerous Tropes Online Misogyny as a National Security Threat
}

\author{
Kyleanne Hunter, PhD, and Emma Jouenne
}

\begin{abstract}
Online misogyny is an under-studied form of information warfare. Often dismissed as "boys will be boys," online misogyny has been allowed to percolate and create communities that have far-reaching impacts. The impacts of online misogyny are not confined to the internet. In this article, the authors show how the ubiquitous nature of online misogyny poses a national security threat. We explore three diverse case studies: the United States military, the incel movement, and ISIS to demonstrate the far-reaching nature of the security threat. Though the nature of the security threats is different, the intervening cause - unchecked online misogyny-is the same.
\end{abstract}

Keywords: misogyny, online radicalization, security

I

n her introduction to Not All Dead White Men: Classics and Misogyny in the Digital Age, Donna Zuckerberg describes how the internet, social media in particular, has allowed a previously undefined and disconnected group to congregate and find a home. This group - composed of men focused on what they espouse to be "traditional values"- has collectively created spaces on the internet where online misogyny is allowed to take root and grow a narrative that

Dr. Kyleanne Hunter is an assistant professor of military and strategic studies at the U.S. Air Force Academy in Colorado Springs, a nonresident fellow at the Brute Krulak Center for Innovation and Creativity at Marine Corps University, and a senior adjunct fellow at the Center for a New American Security. She is a Marine Corps combat veteran and former chair of the Employment and Integration Subcommittee of the Defense Advisory Committee on Women in the Services. The views presented are her own and do not represent her employer or the Department of Defense. Emma Jouenne is an MA candidate in security studies at Georgetown University. She is the associate editor for gender and international relations at the Georgetown Security Studies Review. 
men are being threatened by an ever-modernizing and diverse society. These online communities are not solely a place where frustrated men go to speak ill about women. We find that they produce a politically charged form of information warfare that has consequences to the United States' security. Recent events have shown just how close to home these threats are. On 6 January 2021, an angry mob of mostly male rioters stormed the United States Capitol Building. While their attacks were politically motivated, the rioters displayed aspects of violent misogyny. From donning military attire to literally thumping bare chests to breaking into Speaker Nancy Pelosi's office and putting their feet on her desk, the rioters - most of whom were radicalized online-gave us an upfront view of what violent manifestations of misogyny actually look like. ${ }^{1}$

Zuckerberg's account of how misogyny has found such a stronghold in online communities is reminiscent of Cynthia Enloe's simple question 30 years ago: "where are the women?" ${ }^{2}$ While the internet and social media have allowed for advancements in communication, economics, and education, it has also emboldened and elevated vitriolic forms of misogyny. As Alice Marwick and Rebecca Lewis note, online chatrooms, forums, and social media platforms are the primary means of communication for communities or groups espousing misogynistic beliefs, and the online environment has allowed for the crosspollination of ideas between geographically distant and culturally diverse individuals and organizations. ${ }^{3}$ Yet, this part of the internet is rarely talked about, especially in the traditional security sector. In their introduction to a special edition of Feminist Media Studies on online misogyny, Debbie Ging and Eugenia Siapera discuss how women's experiences online are most often treated as personal matters that government responses have no place in addressing and fall short of warranting a place in public security discourse. ${ }^{4}$ The dismissal of women's concerns comes despite both scholars and victim advocates raising concerns about the degree to which online threats need to be taken seriously and the particularly unique nature of social media to breed "cyber mobs." Victims often find themselves in a double bind-where legally they are at odds with speech protected by the First Amendment while also being socially isolated based on the nature of how they were harassed or attacked.

The categorizing of women's experiences online as private should not come as a surprise. Traditional military and security studies are focused primarily on safety of the state by external threats. Women's security concerns have been historically absent from the traditional security apparatus, treated as private issues to be dealt with once "real security" is handled. ${ }^{6}$ In the physical world, this results in ill consequences ranging from women servicemembers being more susceptible to musculoskeletal injuries due to ill-fitting uniforms and equipment to the underreporting of rape. ${ }^{7}$ The historic absence of women in the security sector does not just harm women. It has also made the conduct of war more 
difficult, especially in culturally sensitive contexts such as counterinsurgency operations. ${ }^{8}$ Feminist scholarship has pushed to begin a meaningful dialogue about the importance of gender equality and gendered security, yet it remains largely absent in conversations of online security, information warfare, or digital propaganda. This has allowed online misogyny to evolve unchecked. ${ }^{9}$

We find that advancements in digital communications have allowed for beliefs held by physically dispersed individuals to coalesce, and the consequences of their beliefs are seen in internal and external security threats. Internally, the unchecked proliferation of misogyny, including among members of the Armed Services, has resulted in a reduction in propensity to serve among young American women, a population critical to the Services reaching their needed force strength and necessary for the conduct of culturally sensitive operations at home and abroad. Externally, gendered online propaganda and targeted "manosphere" discussions are used to recruit violent extremists and create a sense that they are fighting for virtue and values. ${ }^{10}$ These twin threats both pose physical security risks and also undermine the United States' foundational values of civil and individual liberties. Online misogyny must be considered information warfare because it both disrupts and undermines democratic values and has consequences in the real world. ${ }^{11}$ In this article, we use a most different research design with the cases of the United States military, the incel movement, and the Islamic State in Iraq and Syria (ISIS) to show the breadth of the security threat posed by online misogyny. ${ }^{12}$ The article's discussion shows how these threats are linked by the pervasiveness of online misogyny, and it provides recommendations for how the U.S. government, the relevant security institutions, and the private sector should address this phenomenon.

\section{Background: Online Misogyny as Information Warfare}

Misogyny is often trivialized as simply disliking women. But as Kate Manne notes, its roots are much deeper; it is "a political phenomenon whose purpose is to police and enforce women's subordination and to uphold male dominance."13 It focuses on structurally ordering society in such a way that women are degraded, undermined, and denied access to equal rights. In extreme cases, it results in women facing hostile consequences if they violate the norms associated with their role. The strain of misogyny most often found in the online environment is rooted in a belief that society is experiencing a "decline of males" as a response to the increased presence of women in the labor force and sociopolitical positions of power. ${ }^{14}$ Domestically, the loose and diverse collection of men's rights activists adhering to this ideology has become known as the "manosphere." However, online misogyny transcends the manosphere. Hidden in benign and benevolent sexism, adherence to professed traditional values and beliefs about social protection, online misogyny's impacts are diverse. ${ }^{16}$ 
A review of the literature shows two particularly dangerous aspects of online misogyny. First, the specific type of masculinity espoused in this propaganda is strongly linked to violence. The communal and connected nature of the online environment creates a space where individuals holding these beliefs convene, often leading to action in the real world. Second is the ability to propagate falsehood and pseudoscience in a continual and factual seeming manner. The platforms used to spread misinformation provide a sense of legitimacy. Taken together, they present a unique form of information warfare that poses a security threat to the United States.

\section{Violent Roots of Hegemonic Masculinity}

Online misogyny communities are a particularly dangerous manifestation of information warfare because of how closely the form of masculinity practiced in these circles is linked to violence. Their beliefs on masculinity center on toughness, strength, power, and dominance and espouse a hierarchical ordering principle that views women as "less than" due to a rigid "gender system." ${ }^{17}$ This ideology creates rules of distinctive separation linked to beliefs about masculine and feminine norms, and it attributes higher value to things perceived as masculine. Men and women have distinct roles and places in societies, and it is a man's duty to engage in violence to preserve that order. It is important to note that gender norms and practices differ based on cultural differences. ${ }^{18}$ However, the hierarchical gender system that results in violence is a constant across cultures. Though this belief system is often espoused through the language of honor-men being "just warriors" to protect women's "beautiful souls" - it is often manifested through less-than-honorable violence. ${ }^{19}$ This is exemplified in M. Christina Santana et al.'s finding that men who reported adhering to these traditional beliefs about masculinity engaged in sexual and intimate partner violence significantly more than those who did not. ${ }^{20}$ Belief in men's dominance over women is also correlated with participation in larger-scale political violence. ${ }^{21}$ Strong adherence to patriarchal values coupled with a belief that men are "tougher" than women creates what Karen Brounéus, Elin Bjarnegård, and Erik Melander describe as an "honor ideology."22 Men who subscribe to this ideology are more likely to engage in violence specifically to counter gender equality norms and policies. Joshua $\mathrm{M}$. Roose further expands on this linkage. He finds this ideology leads to beliefs that women's empowerment has left men victimized and discriminated against. They play out their anger and resentment through violent acts, justifying them as merely reclaiming the power they believe is rightfully theirs. ${ }^{23}$ Online, men go to great lengths to create a persona steeped in the trappings of their views on masculinity. In analyzing identity performance in this space, Joseph A. Vandello et al. finds that there is a certain "precarious manhood" that is overacted when there is a perceived threat from 
advancements in women's rights or social position. ${ }^{24}$ The degree to which violence-or speech inciting violence-is a result of this practice is proportional to the threat that men feel. ${ }^{25}$ The more that men are pushed to believe that women are threatening what they view to be the "natural order," the more accentuated their violent reactions will be.

While individuals holding such beliefs are harmful to those in their immediate surroundings, the internet magnifies and accelerates these feelings, amplifying the damage that can be done. The internet is adept at facilitating political assemblages that unite around emotional involvement and ideals. ${ }^{26}$ As Laura Bates notes, the internet adds a layer of social interaction to the users' experience and reinforces the density of their relationships. ${ }^{27}$ It continues to move misogyny from a fringe idea to a ubiquitous feature of the online environment. During the past two decades, we have seen an uptick in radicalized violent organizations, hate groups, and other forms of misogyny on diverse social media platforms. Easy access to technology has increased misogynistic radicalization at a pace with which neither the security sector nor the law has kept up. The widespread recruitment that the virtual world has facilitated has moved misogyny into the information warfare domain. ${ }^{28}$ There is a lack of preparedness and coordination among government and private security agencies to mount an appropriate and proportionate response to this new threat. This protean threat is evolving in two related "war zones" with shifting and ill-defined borders: cyberspace and the information space.

\section{The Firehose of Falsehood}

As the recent Capitol attacks on 6 January 2021 and President Donald J. Trump's second impeachment show, information is a political tool that encourages violence. Such violence inciting rhetoric is an example of Christopher Whyte's view of information warfare as a tool that threatens security through its disruption and undermining of democratic processes and values. ${ }^{29}$ The threat posed not only harms women, but as will be shown, undermines the very foundations of the United States' principles. The threat posed by online misogyny is bolstered through the use of language. Online misogyny adheres to what has been dubbed the "firehose of falsehood" approach to disinformation propagan$\mathrm{da}$, where lies are told often and confidently enough that they become adopted as truths. ${ }^{30}$ The increased customization and specificity of individuals' online experience helps to accelerate the firehose of falsehood effect. As social media, search engines, and online chat communities work to personalize the experience for users, online echo chambers are created that reinforce false narratives to the point that they are accepted as truth. ${ }^{31}$ This phenomenon is accelerated when information comes from official-sounding sources. Soroush Vosoughi, Deb Roy, and Sinan Aral found that false information spreads faster and is more 
quickly believed than truthful information online due to both the novelty of the information and the feelings of connection to the source. ${ }^{32}$

To strengthen the firehose of falsehood, official sources are often cited and are distorted to meet a false narrative. This is seen in examples such as the use of a discredited interpretation of the Pareto Principle arguing " $20 \%$ of men get $80 \%$ of women" to general officers asserting that women are too delicate to be a part of infantry units. ${ }^{33}$ In surveying the top four studies of actual fake news in the United States, John Corner finds that in the majority of instances, fake stories cite an official data source or official agency to attempt to lend credibility to their claims. ${ }^{34}$ Yet in asserting their claims, the data is taken largely out of context or misused. An example of this is the use of a Centers for Disease Control and Prevention (CDC) national prevalence survey on intimate partner violence on incels.co to assert that "men are more likely to suffer intimate physical violence than women." 35

Manipulation of official-sounding data serves to embolden misogynistic beliefs and recruit dissatisfied individuals. The official-sounding narrative allows for unfounded information to appear more truthful. The type of disinformation contained in the firehose of falsehood paints women as both victims (i.e., losing their real womanhood to overly feminist Western society) as well as perpetrators (i.e., responsible for the spread of COVID-19 or the loss of military effectiveness). This dual narrative results in a compounded negative view of women. Social media has created a platform that has given these views a sense of legitimacy and fueled public debate. ${ }^{36}$ This gendered disinformation creates a security threat through both pushing women out of the formal security sector and providing justification for violence against those who hold values of egalitarianism.

\section{Methods and Hypotheses}

We use a most different research design to show the far-reaching and diverse impact that online misogyny has on national security. The United States military, the incel movement, and ISIS are diverse organizations, with missions, ideology, and in-group practices that differ greatly. ISIS represents a direct threat to the physical security of U.S. interests while the incel movement undermines democratic norms and values of equality, and the military is responsible for protecting U.S. national security. They do, however, have similarities. They are male dominated and have historical anti-women biases that are both formal (i.e., legal restrictions on the jobs women in the military are able to hold) and informal (i.e., biases against women being in nontraditional roles). Yet, one similarity is striking - they all rely on the online environment as a primary communication tool, making them susceptible to online misogyny. The experienced consequences of online misogyny represent the varied ways in which 
information warfare harms U.S. security. The case of the military represents a threat via omission. It shows how misogynistic speech and propaganda harms the United States through excluding or omitting certain groups from the security sector. This omission makes it easier for violence to be enacted against the continually underrepresented group. The continued cycle of rhetoric and abuse has left the United States in a vulnerable position. The incel movement and ISIS represent threats through commission. Misogynic rhetoric incites individuals to engage in violence in a way they would not absent the gendered rhetoric. Though the types of security threats appear dissimilar, it is important to study them collectively because the driver of the security threat is the same-and mutually reinforcing. The gendered rhetoric used to incite violence has largely slipped through the cracks of the traditional security apparatus, making the United States and its interests susceptible to attacks. However, the diverse perspectives needed to address this security concern are being pushed out by the very same phenomenon. We need more women's perspectives in security to fully address the gendered nature of violent extremism, yet online misogyny is pushing them out of the security sector. While anti-women sentiments have existed long before the internet, the online environment has accelerated its spread and helped to grow its reach.

Using a most different research design in this case shows how sizable of an impact online misogyny has on security. As Carsten Anckar notes, most different designs are beneficial for isolating phenomena that interact with diverse systems in potentially different ways but ultimately have a common outcome. ${ }^{37}$ The ubiquitous nature of online misogyny is such a phenomenon. It is not limited to one group. A survey of U.S. social media posts found that more than one-half contained misogynistic content, even if not explicitly part of an explicit anti-woman group. ${ }^{38} \mathrm{~A}$ most different design is also important for identifying a set of solutions that can impact multiple problems simultaneously. As the article will show, policy and practice interventions that address the dangers posed by the manosphere have impacts that address multiple security concerns. Such interventions are not only resource efficient but also address a root cause, leading to more lasting change.

We tested two hypotheses to determine the relationship between online misogyny and national security.

H1: Online misogyny makes recruiting into the military more difficult

H2: Online misogyny intensifies violent tendencies of radical groups

H1 tests the internal security threat that online misogyny poses. Recruiting women is vital for national security, both to meet needed recruiting numbers and to ensure the military has access to the skills it needs for current and future conflicts. ${ }^{39}$ If this hypothesis holds, we will see a reduction in women's pro- 
pensity to serve and/or a higher rate of attrition for women once they join the Service as a result of online misogyny. $\mathrm{H} 2$ tests the external security threat of online misogyny. The strong link between hegemonic masculinity and violence leads to physical insecurity for the United States and its interests abroad. If this hypothesis holds, we will see an uptick in violent attacks as a result of online misogyny.

Research to test $\mathrm{H} 1$ was conducted through focus groups of active duty military servicemembers. Focus groups were conducted between 2015 and 2019 during one author's tenure on the Defense Advisory Committee on Women in the Services. They were conducted each spring on bases representing all five Services (Navy, Marine Corps, Army, Air Force, and Coast Guard). Participants were divided by rank (junior enlisted, senior enlisted, and officer) and gender to create an environment that was conducive to free and honest discussion. Focus group protocols were grouped into three main categories: propensity to serve, recruitment and retention, and beliefs about belonging. Each focus group was also given a miniature survey to capture demographic information, including years of service and plans for retirement/separation. All data collection instruments were ruled exempt by ICF's institutional review board with concurrence from the Department of Defense's Office of the Undersecretary of Defense for Personnel and Readiness to ensure protection of human subjects. Focus groups were transcribed by a contracted ICF research team. Analysis of transcribed focus groups was undertaken by a diverse team without existing conflicts of interest. Content review was done during a period of four weeks with weekly meetings for discussion of leading emergent themes and to ensure inter-rater reliability. A total of 2,834 individuals participated in focus groups. The gender breakdown was 44 percent identifying as women, 52 percent identifying as male, and 4 percent declining to identify. Thirty-two percent of participants were officers and 68 percent enlisted. Women and officers were oversampled to ensure diversity in opinions. $\mathrm{H} 2$ was tested through discourse analysis of posts by ISIS and the incel movement. Discourse actively constructs the social world. Discourse analysis allows us to gain insight into social interaction and motivation for action, as discourse creates a world that appears as real or true for the writer as the physical world around them. ${ }^{40}$ The authors coded posts from incels.co, from March-June 2020. The incels.co forum is host to more than 12,000 members. We analyzed a 500-message sample, representing a crosssample of key subforums on incel.co. The keywords "women," "femoids," "foids," "deserve," "die," and "violence" were evaluated for frequency and nature of occurrence. We also coded the interrogation of Alek Minassian, perpetrator of an attack in Toronto, Canada. ${ }^{41}$ This provided the authors with insight into slurs or speech that were not explicitly violent yet signaled violent intent.

Additionally, we coded articles from three newspapers: Al-Naba, Dabiq, 
and Al-Rumiyah from 2014 to 2020. These outlets were chosen based on the size of their readership, the frequency of publication, and their role as recruitment tools by ISIS. Al-Naba is a weekly newspaper published since 2014 by ISIS. Dabiq is an online magazine, which ran from 2014 to 2016. Al-Rumiyah replaced Dabiq in September 2016. They serve as the primary recruitment tool for new members. The articles extracted from those outlets are therefore assumed to be representative for propaganda contents of the Islamic State and serve as appropriate objects for the analysis. Articles were coded for gender roles (how men and women were portrayed), incentives for committing violence, and descriptions of those who engaged in violence.

\section{Findings}

\section{Testing H1-The Internal Threat: Shutting Women out of Security}

The relationship between misogyny and the U.S. military is not a new development. The military has and continues to be criticized as an overly white, male institution whereby both through commission and omission women have been marginalized. ${ }^{42}$ However, prior to the advent of the internet, the impact of misogyny was more limited. The prevalence of the online environment has accelerated and elevated the impact of misogyny. The direct impacts of institutional misogyny have been persistent and violent. From the Tailhook scandal to the murder of Army Specialist Vanessa Guillen, women within the military have directly suffered the results of institutional misogyny.

While the existence of misogynistic expressions as part of military culture are nothing new, the online environment is leading to new expressions and more far-reaching impacts. No longer confined to the barracks or isolated events, young recruits (or potential recruits) are being exposed to these sentiments earlier and more frequently. The nature and degree of exposure has resulted in different types of outcomes. In addition to the direct threat to women, there is also an impact on propensity to serve. Social media is a primary medium used by young people to gain information about their future careers. ${ }^{43}$ Even beyond career searching, American teens spend approximately nine hours per day consuming digital media. ${ }^{44}$ Given the prevalence of digital communication to youth, it is nearly impossible for them not to engage with some form of misogyny online. The result is a reduction in the talent pool from which the military can draw.

Analysis of focus group transcripts finds support for $\mathrm{H} 1$ : online misogyny was a key factor in women's decision to either not join or to leave the military. We found two primary causal pathways linking online misogyny to military recruitment and retention challenges. First, there were direct misogynistic attacks from male servicemembers against their female counterparts. These attacks were often perpetuated by male members of women's units and led to hostile 
workplaces and reduced retention. Second, there were generalizations made by military groups or pages online about the character and necessity of women's service in the military. Though less targeted, the nature of the messenger in these instances elevated the impact of this pathway.

\section{Personal Attacks from Unit Members}

Like all Americans, servicemembers often use social media to share their personal life, posting photos from vacations and celebrating life's accomplishments. Many focus group participants discussed how social media is the primary way to stay in touch with physically distant friends and family. However, it has also become a means by which women are being harassed and targeted. Most commonly, servicemembers described social media as a medium by which senior men were able to harass more junior women. As one junior enlisted member noted:

You can't say no to their friend request because you don't know if this is an official request or something else. ${ }^{45}$

Most junior women in focus groups expressed being uncomfortable with at least some of the comments that their senior male "friends" made on their posts or comments. Another junior enlisted woman noted:

It made me uncomfortable the way he was always talking about my body ... sexualizing it, talking about the things he liked ... all of a sudden I was no longer a [servicemember] but a piece of meat. ${ }^{46}$

Women reported feeling uncomfortable or unable to report these issues, since the perpetrator of the harassment was often in their direct chain of command. The net result is women leaving the Service due to a feeling a lack of belonging and a lack of belief that their concerns will be adequately addressed. In the miniature survey accompanying focus groups, women outpaced men nearly 2:1 in saying they were planning on leaving the Service as soon as they were eligible for separation. The disparity was even greater for officers, with only 15 percent of women saying they had plans to stay in past their initial obligation, compared to 62 percent of men. The majority of servicemembers participating in focus groups cited the discomfort they felt online as a primary factor in their decision to leave the Service.

Personal online attacks were not isolated to social media "friends." Women often reported that photographs of them from official events- whether their personal command image or official pictures from unit functions-were used maliciously in the creation of memes and shared online. The rhetoric used in these memes discussed rape and murder, evidence of the link between the type 
of masculinity performed by individuals engaged in online misogyny and the potential for violence. This rhetoric has intensified as more women have entered the Services. It is likely that women in the military are experiencing a backlash in response to their perceived challenge to the masculine status quo. ${ }^{47}$ The most prominent instance of this was the Marines United scandal. ${ }^{48}$ Though Marines United received prominent media coverage, this phenomenon was widespread. Several woman officers who participated in the focus groups reported having had at least one official photograph taken and turned into a meme. It is important to note that these social media posts persist despite the Services having guidelines for all unofficial postings. For example, Marine Corps guidelines include content that "is defamatory, threatening, harassing, or which discriminates based on a person's race, color, sex, gender, age, religion, national origin, sexual orientation or other protected criteria" as punishable under Article 92 of the Uniform Code of Military Justice (UCMJ). ${ }^{49}$ That such posts continue suggests that individuals believe that the guidance is unenforceable, or that leadership does not care to address it.

The fear of continued attacks on social media has negative impacts on women's propensity to serve. As one female officer noted:

The recent Marines United scandal . . w was very discouraging. ... If I was thinking of joining, I would maybe look at something else. ${ }^{50}$

Women servicemembers saw this as not only impacting them but the future of the Service. In discussing her experiences with being attacked online, a female officer noted:

For me it is too late, but that sexual stuff is everywhere. I would not let my daughter join with all that. ${ }^{51}$

The military relies heavily on currently serving members for recruitment. In 2019, 80 percent of new enlistees had a family member who had served in the military. ${ }^{52}$ Online misogyny is not only harming the current force, but it has the potential to harm the force for generations to come.

\section{How Military Social Media Pages Represent Women}

Focus groups almost unanimously noted that social media was a means by which the Services could — and should — share official information with their members as well as communicate with the public about military life. More than 66 percent of new recruits cite the Services' social media as a primary source of information they referenced prior to going to their initial training. ${ }^{53}$ The increased prevalence of official command social media pages is a clear attempt by the Services to speak directly to the younger generation in the way that is most 
effective for them. The official nature of these pages exemplifies the impact of an official messenger perpetuating damaging information. From the official Marine Corps' Instagram page posting "Saturday Is for the Boys” under a picture of infantry Marines, to the Army having less than 1 percent women represented in official social media, the notion that men are the ideal warfighter continues to be perpetuated by official sources. ${ }^{54}$

The consequences of this can be seen in women's beliefs about their service. When asked directly about their feelings on service and the pathway to serving, most women participating in focus groups indicated that the representation of service women on social media discouraged them from serving. As one enlisted woman noted:

As females, we are doubted immediately. For males, it is "At least you tried." For females ... the way they represent us we know we are going to be doubted up front [when joining]. Most people just don't want that. ${ }^{55}$

For those who chose to serve despite feelings that they did not belong, the majority felt dissuaded from serving in combat arms jobs because the Service had portrayed them as belonging exclusively to men. As a senior enlisted woman noted:

I went back home as a recruiter's assistant. . . . There was a girl who wanted nothing more than to be in a [combat occupational specialty]. I heard [the stereotype] echoed by the recruiter. He [said], "Do you know what this is going to entail?" He was doubting her mental strength. Echoing what he heard about women not being able to do the job. ${ }^{56}$

Many servicemembers feel that there is no way that this can be overcome by current leadership. As one officer stated:

It's crazy. . . . You get [online and see inappropriate posts] on [my Service's] Facebook page, and what can you do about it because every day it's something new, and in the comments people feel like they have the rights to express all their nasty feelings ... [these pages] have propped up people who feel the need to express everything before they think about it and don't realize how many women see what they post. ${ }^{57}$

Social media was also largely responsible for misinformation being spread about women's ability to meet physical standards for service in combat arms roles and the impact that women were having on the effectiveness of these units. When asked directly about their biggest concerns, most male servicemembers 
responded that they believed that standards were being lowered to accommodate a "social justice" agenda at the expense of military effectiveness. But when asked why, none could point to an official source. One junior enlisted man noted:

I read that on the military.com source. But I haven't heard anything else more reputable. I haven't heard commanders say anything, so I believe military.com. ${ }^{58}$

A senior enlisted man noted:

I've seen more articles from Facebook about what's going on in [my Service] than from my own command. ${ }^{59}$

Women servicemembers recount the impact that the perpetuation of social media misinformation has on their careers. One junior enlisted woman in a ground combat specialty noted:

When we were integrating, they were like, "Standards are going to go low," and I've heard men in our unit talk about [physical fitness] standards, and they are jealous, like, "The females have low standards and I want that." It's just too much. They don't trust me and there is no way I can get them to believe I am doing the same work as them.

Despite all occupational specialties being open to women, and the Services creating gender integration implementation plans to recruit and retain more women, online misogyny is harming the ability of the Services to recruit and retain this needed demographic. Women remain less than half as likely to join the military as men, and when they do join are 28 percent more likely to leave the Service and are promoted at lower rates than their male counterparts. ${ }^{60}$

\section{Testing H2-The External Threat:}

\section{Online Misogyny to Promote Violence}

A focused backlash against "modernization" is increasingly being used by violent extremists. ${ }^{61} \mathrm{~A}$ particular aspect of modernization that these groups target is the increased role of women in sociopolitical life. They cast feminism and the Western lifestyle as the enemy to promote the use of violence. Traditional gender norms create a very simple frame through which to view the world, and the online environment allows for the amplification of ideology that leads to violence.

To test H2, we analyzed the rhetoric of the incel movement and ISIS. We find support for online misogyny intensifying the likelihood of violent attacks by these groups. This is seen through two primary mechanisms. First, the online 
environment intensifies individual feelings of resentment over what they believe is lost power and provides an impetus for collective violence. And second, there is a call back to "traditional" norms as justification for men's dominance over women. The imagery of purity, honor, and duty surrounding this rhetoric further intensifies the frequency and intensity of violence.

\section{Regaining “Lost" Power}

Online misogyny shifted the incel movement from a platform for discussion on the negative impacts of rigid gender norms to a forum for radicalization into violent action. ${ }^{62}$ Central to the incel movement's rhetoric and beliefs is the idea that women are superficial beings who are only attracted to "genetically superior men" (referred to as "Chads"). ${ }^{63}$ The belief that women "stole" power from men has spurred physical attacks. Elliot Rodger, author of the 133-page "Manifesto on Women," conducted one such attack. Rodger shot eight people in Isla Vista, California, in 2014 before killing himself. Since Rodger's attack and the proliferation of his manifesto, there have been four copycat attacks: Chris Harper-Mercer (Umpqua Community College shooting in Los Angeles, California), William Atchison (Aztec High School in Aztec, New Mexico), Alek Minassian (van attack in Toronto, Canada), and Scott Beierle (hot yoga shooting in Tallahassee, Florida). ${ }^{64}$ The rhetoric of these attackers shows the connection between the belief that power has been taken from them and the need to commit violence to right this injustice. As Alek Minassian posted on his Facebook page just before his attack:

Private (Recruit) Minassian Infantry 00010, wishing to speak to Sgt 4chan please. C23249161. The Incel Rebellion has already begun! We will overthrow all the Chads and Stacys! All hail the Supreme Gentleman Elliot Rodger! ${ }^{65}$

Incel forums promote the belief that women should be submissive to the natural power of men, and men should be able to exert their physical dominance and have sex without being rejected. Discussing familial relations, this is seen in patriarchal dominance:

I'm more for Nathan Larson's version where the families are an individual entity and in that family the father decides where his daughter goes. I.E [sic] the father decides who the female marries to, and this can be at any age. The father, being the head of the household and the creator of the daughter, should also decide where she goes (as long as its [sic] monogamous, same race, heterosexual etc.). ${ }^{66}$

When society rejects them, they blame Western feminism for undermining 
the natural order. ${ }^{67}$ Their rhetoric quickly turns to celebrating violence in this regard:

Everytime i $[$ sic $]$ see on the news a woman that was raped, killed and whatnot. I just applaud the based one who took the time and effort to dispatch such useless garbage in the world. ${ }^{68}$

While their online rhetoric may sound abhorrent, the security threat comes from its translation into the physical world. In his own words during his interrogation with a police officer from the Toronto Sex Crimes Unit (identified in the transcripts as "THOMAS"), Alek Minassian explained how his participation on forums spurred him to action. The online environment was attractive because of the "style of conversation" of the members who shared his opinions and access to individuals like Elliot Rodger who he admired:

MINASSIAN: I felt kind of proud of [Elliot Rodger] for his acts of bravery.

THOMAS: Okay alright and what about how you started to . . . change your thinking? Was any of that going on [in your conversations]?

MINASSIAN: I was starting to feel . . . radicalized at that time.

THOMAS: When you say radicalized what do you mean by that?

MINASSIAN: Meaning I felt it was time to take action and not just sit on the side lines and just ... fester in my own sadness ...

THOMAS: Right but then as you got to know Elliot [Rodger] and understand his ... mission and what he had done you began to become radicalized in terms of your thought process. ${ }^{69}$

Minassian goes on to discuss how his violent actions were celebrated in the online environment:

MINASSIAN: Yes [after the attack] quite a few people ... were congratulating me.

THOMAS: Okay.

MINASSIAN: And in fact I remember there was one poster who said he was from Edmonton and he would be planning a similar uprising in November ... of this year.

THOMAS: Of this year, okay, okay and what ah specifically did he say in terms of what he was going to do?

MINASSIAN: He said ... hey thanks man . . . you you've 
given me great inspiration, November 15 Edmonton the continuation of the rebellion. ${ }^{70}$

The amplification of misogynistic sentiments in the online environment has spurred direct violence. The case of the incel movement shows how the combination of the particularly violent form of masculinity practiced, coupled with the legitimacy granted by online forms has deadly consequences.

\section{Return to Traditional Societies of Order, Honor, Duty, and Purity}

ISIS frames itself fighting against the Western oppression of Muslim populations and aims to create its own political system across boundaries. More than 140 violent attacks have been claimed by ISIS, making it one of the deadliest terrorist organizations.

Most analysis of ISIS's propaganda and discourses focus on its rejection of the Western lifestyle. Most gendered analysis of ISIS focuses on the seemingly exceptional nature of their decision to deliberately recruit women. ${ }^{71}$ Yet, a discourse analysis rooted in understanding the role of online misogyny shows a clear instrumentalization of gender norms as a catalyst for its violent action. In crafting recruitment messages, ISIS has created a narrow lane in which women are allowed to operate. Women can be mothers and wives and occasionally suicide bombers. ISIS uses this narrow view of a woman's role to deconstruct the narratives on gender equality promoted by the West:

My Muslim sister, indeed you are a mujāhidah, and if the weapon of the men is the assault rifle and the explosive belt, then know that the weapon of the women is good behavior. ${ }^{72}$

The Dabiq column “To Our Sisters" directly addresses the perceived "harms" that Western feminism has enabled:

Indeed, when the Sharīah of our Lord was eliminated, the laws and rulings of the kuffār gained power in the lands of the Muslims, Islam was shamefully abandoned, and faces turned towards promiscuous Europe, the voice of falsehood rose and with it the voices of those hostile towards the people of the religion, and the cancer of those who legislate besides Allah ate away at the Ummah's body. They prohibited what He permitted, and permitted what He prohibited, and one of the most manifest things that they ruined and defamed in defense of women and their rights — as they claimed — was polygyny. They utilized their podiums to that end, including the podiums of the kufrī parliaments and the secular TV channels, and placed on these podiums howling dogs, fools who do not per- 
ceive nor know their foolishness. Their poisoned words crept into the hearts of women from the lands of the Muslims, to the point that we almost couldn't find a single woman that is accepting of this issue, except for those whom Allah protected. ${ }^{73}$

In conjunction with promoting an ideal womanhood that stands counter to Western values, ISIS employs a gendered focus on humiliation to spur violence by Muslim men. They frame the occupation of territory as another example of how Western feminism is stripping power away from men. They amplify this through the use of imagery involving children and women to shame men. For example, in Al-Rumiyah:

so what is the matter with those men who . . . continue to remain behind, having laid down their swords, even watching passively as they are surpassed on occasion by the women of the Ummah?! Such was the case on 11 September 2016, when three muwahhid [monotheist] sisters carried out a daring attack on a police station in Mombasa, Kenya, targeting the security forces of a Crusader nation, and doing so in support of the Islamic State. . . . With all three sisters attaining shahadah [martyrdom] after voluntarily shouldering a duty that Allah had placed on the shoulders of the men of the Ummah. . . . The Sunna of the Prophet directed its incitement for physical combat towards the men of the Ummah. Why, then, do so many men continue to neglect their duty? Why have they laid down their swords and armed themselves instead with one excuse after another for not fulfilling their obligation?... . And why have they sat back idly — if not cowardly — while the Ummah's chaste, noble women, for whom jihad is a voluntary and righteous deed, stood in all their bravery to fulfill the duty of men?!. . . . They can take a lesson from their courageous sisters. These men can learn what it means to be sincere to Allah by reading the last testament of their sisters in Kenya who have joined the ranks of the shuhada [martyrs]. ${ }^{74}$

The online environment is used to broadcast recruiting messages. While their online magazine published in both English and Arabic allows ISIS to have an international audience, it also uses open platforms such as Telegram, Facebook, or YouTube to disseminate videos and imagery to shame men into joining their ranks. Such rhetoric plays on the discomfort men who hold traditional gendered beliefs experience at the thought of a woman or child being more 
empowered than them. It follows the pattern that Michael S. Kimmel finds in linking emasculating language to taking up arms against the West. ${ }^{75}$ The persistence of attacks attributed to ISIS have continued even as political leaders in the United States and abroad have praised the "defeat" of ISIS's hold on territory. ISIS claimed responsibility for attacks that have resulted in more than 200 deaths in the first half of 2020 and continued its typical escalation in Syria during the holy month of Ramadan (24 April through 23 May) despite the COVID-19 pandemic. ${ }^{76}$ The inspector general warns that attacks may continue to increase if pressure is reduced due to pandemic responses. ${ }^{77}$ Indeed, the case of ISIS shows how the threat of violent extremism transcends physical territorial threats, and it illustrates the particularly dangerous role that the online environment plays in inciting violence.

\section{Discussion}

\section{The Combined Security Threat}

The cases of the U.S. military, the incel movement, and ISIS highlight the holistic nature of the security threat posed by online misogyny. The nature of attacks being perpetrated by violent radicalized groups such as the incel movement and ISIS have a very gendered dimension. To combat them, the military must take a gendered approach to understanding the security landscape. However, the very same phenomenon that is leading to these violent attacks is also hindering the military from recruiting and retaining the people needed to meet this threat.

The need for women in the military extends beyond meeting force strength numbers. The wars in Iraq and Afghanistan highlighted the operational necessity of women's service in culturally sensitive conflicts. ${ }^{78}$ Women have unique, gendered roles that cannot be duplicated by their male counterparts. ${ }^{79}$ Though the United States is pivoting away from its role in Iraq and Afghanistan, the gendered threat remains. As shown in the case of the incel movement, gendered extremism is not unique to the Middle East, and as the United States pivots to near-peer competition, understanding how cultural gendered norms contribute to violence will continue to be important. In the near-peer environment, cultural competency in the online environment will be a key factor in ensuring U.S. security. China and Russia are both adept at online disinformation campaigns. And while their disinformation is not necessarily misogynistic in nature, it is culturally specific. New research is highlighting the importance of diverse teams - especially gender diverse teams - at identifying online misinformation within specific cultural contexts. ${ }^{80}$ An effective force of the future will require a broad recruitment pool.

Numerically, it should not be difficult to recruit women. In every state, 
women's Service eligibility outpaces men's by an average of 2 percent. ${ }^{81}$ Women also have an increased high school graduation rate and are outpacing men in the science, technology, engineering, and math (STEM) fields, giving them the hard skills necessary to combat the growing online threat. This should be good news - as more women are needed, more are becoming eligible and have the desired skills for service. However, despite having a greater eligibility to serve, women have less than half of the propensity to serve as men -7 percent compared to 15 percent. ${ }^{82}$ Further, women's propensity to serve has remained relatively unchanged - 6 percent in 2001 compared to 7 percent in 2017-despite efforts by the Services to target their recruitment. Women feature prominently in the recruiting campaigns for all branches of the military. A prominent example of this is the Marine Corps' "Battles Won" recruitment campaign. The first ad in the campaign series, "Battle Up," features a female protagonist, tracing her life from high school student to Marine on the battlefield. This ad garnered a higher-than-average favorability rating (58 percent compared to 49 percent for all other ads) among all recruits, yet still did not lead to an increase in women's overall recruitment. ${ }^{83}$ At the highest levels of government, this combined security threat has been recognized. The Department of Defense's (DOD) implementation guidance for the Women, Peace, and Security Act of 2017 directly addresses the need for a more diverse fighting force to counter today's threats. ${ }^{84}$ Defense Objective 1 specifically addresses this, stating, "The Department of Defense exemplifies a diverse organization that allows for women's meaningful participation across the development, management, and employment of the Joint Force." ${ }^{85}$ However, without addressing the threat of misogyny across the spectrum, this will not be met. There is evidence that the military is beginning to address online misogyny as a security threat. Threat briefings received at Joint Base Andrews, Maryland, in 2019 included a slide on incels in order to "educate commanders on the behaviors associated with the group to safeguard Airmen." ${ }^{86}$ Secretary of Defense Lloyd J. Austin III is expanding these efforts. On 2 February 2021, he called for a Department of Defense-wide stand-down to address the risk of extremism among servicemembers. ${ }^{87}$ Such efforts are an encouraging step, as the prevalence of harmful ideals is evidenced by participation by active duty military and veterans in the 6 January 2021 insurrection at the U.S. Capitol. ${ }^{88}$

In addition to hindering the United States' ability to meet force strength requirements, online misogyny continues to facilitate physical violence toward U.S. interests. The case of ISIS shows how territorial defeat alone is not enough to claim victory over an adversary. While U.S. security officials were focused on defeating the physical caliphate, ISIS continued to build support in the online environment, using hatred toward Western values of equality to recruit indi- 
viduals and groups to commit violent attacks in areas beyond Iraq and Syria. A gendered approach will address many of these blind spots in security and result in greater overall security.

\section{Recommendations}

To combat the threats of online misogyny, the United States security sectorincluding the military - must fully internalize the importance of gendered approaches to security. To do this, it must not only recognize the importance of the online environment to national security but take a particular gendered approach to understanding how this domain impacts security. In the 20 years since the passage of United Nations Resolution 1325, there have been attempts at integrating women, peace, and security into security operations, yet both top-down and bottom-up attempts have fallen short of holistically addressing the threat that online misogyny poses. ${ }^{89}$

Recruiting more women into the security sector is clearly a start, but simply adding more women on its own is not enough. The security sector is a historically masculine enterprise and adheres to what Kyleanne Hunter and Rebecca Best describe as cognitive-institutional reinforcement. ${ }^{90}$ The military and other aspects of the security sector are institutions that rely heavily on a masculine view of warfighting and have historically expected women to adhere to these norms when they join. This requires women to act like "little men" to be successful. This not only has an impact on women's identities but undermines the ability of the military to leverage women's perspectives. When integrating women, the military must do so in such a way that allows them to maintain their unique perspectives.

This requires addressing training, education, and equipment. Fully integrating all training units is a necessary first step. Gender-integrated teams perform better at solving complex problems and do so more successfully when they build task-based cohesion during initial training. Separating men and women during training reinforces the idea that women's perspectives are inferior to men's, while integration builds better teams and sets a baseline for acceptance and appreciation of the unique perspectives women bring. ${ }^{91}$ Beyond initial training, gender perspectives must be integrated into all levels of military education to reaffirm and recognize the importance of women's perspectives. While top-level civilian leaders have recognized the importance of women's perspectives, operational commanders have dismissed women's perspectives as secondary to traditional hard security outcomes. ${ }^{92}$ Introducing the connection between women's security and hard security outcomes throughout military education will result in more robust security outcomes.

The nature of military equipment also has an important role in ensuring that women's unique perspectives are appreciated and integrated. Ill-fitting 
equipment not only results in an increased likelihood that women servicemembers will be injured but also creates a cultural feeling that women ought to be little men. ${ }^{93}$ Properly fitting equipment, conversely, optimizes women's performance and allows for them to not only better contribute to military missions but to do so while building a culture that also respects them and leverages their unique skills. ${ }^{94}$ Indeed, through training and equipping, the military Services can meaningfully address some of the underpinnings of misogyny and leverage the unique skills of women to combat broader security threats. While the military has made strides in integrating gendered perspectives into some aspects of warfare, information and cyber warfare are lacking in this regard. ${ }^{95}$ Yet as shown here, gendered activity, specifically online misogyny, is responsible for increased violence.

Taking a gendered approach to online activity and propaganda will also help with countering violent extremism efforts (CVE). CVE focuses on using noncoercive measures to dissuade radicalization. ${ }^{96}$ A more nuanced understanding of gender and how misogyny is manifested is necessary to effectively understand the drivers of online misogyny and how to dissuade individuals from becoming radicalized online. A DOD-sponsored review that takes a gendered perspective to online radicalization both at home as well as in key potential hotbeds is a necessary first step. Such an approach should be three-pronged. First, it should include current and post-conflict countries (such as Iraq, Syria, and Afghanistan) from which groups like ISIS typically recruit. Second, it must include new hotbeds of recruitment-primarily the United States' European allies - as well as an internal review. The current global pandemic has exposed new economic and social tensions that may increase the likelihood of radicalization. And third, it must include our near-peer competitors in Russia and China to uncover how they are using gender to further disinformation.

Government counterterrorism and intelligence services must also recognize gender-driven violence as a form of extremism. This will have a two-pronged impact. First, it will empower local law enforcement to take meaningful action against extremism. And second, it will help to legitimize and guide private actors working in the combating violent extremism sector. Activities in Canada offer an example. In 2019, the Canadian Security Intelligence Service recognized gender-driven violence as a form of ideologically motivated violent extremism. That year, police charged a 17-year-old who had murdered a young woman with a machete in a massage parlor with "incel ideology," a first of its kind charge.

The Global Internet Forum to Counter Terrorism and Tech Against Terrorism have developed the Terrorist Content Analytics Platform (TCAP). TCAP alerts users to content associated with designated terrorist organizations, archives the material, and facilitates discussion between online platforms, civil 
society, law enforcement, and academia to improve classification and moderation of illegal content. Their classification depends on official designations of terrorist entities. The Canadian Security Intelligence Service recognition of gender-driven violence as a form of ideologically motivated violent extremism, and the recent addition of The Base and The Proud Boys to the list of terrorist organizations is allowing for online misogyny to be captured. While it is too soon to know the impact of these changes, this is promising for ensuring early warnings of violence.

The Violence Against Women Act (VAWA) is an additional policy that has promise for combating this form of online extremisms. President Joseph R. Biden made passing the reauthorization of VAWA a centerpiece of his campaign. As his administration pushes for the policy, it has the opportunity to include legislation against online gendered abuse. Despite the legal complexity of attribution in online violence, lawmakers have an opportunity to strengthen legal protections and implement early detection of potential violence.

This comprehensive gendered approach will address both the internal and external security threats posed by online misogyny. It will also reduce the prevalence of the form of misogyny most associated with violence. Empirical evidence shows that ensuring gender equality at the structural level reduces the likelihood of the forms of violence most associated with hegemonic masculinity_including rape (or the threat thereof), intimate partner violence, and politically motivated attacks against women. ${ }^{97}$

It also will help to reduce the firehose of falsehood. More comprehensive gendered approaches to security in the online environment will ensure that fewer pieces of disinformation fall through the cracks. As men and women are socialized differently, they are able to identify different aspects of disinformation. ${ }^{98}$ Deliberately ensuring that diverse perspectives are part of the totality of security operations will help to detect early signs of misogynistic disinformation and ultimately keep the United States more secure.

\section{Conclusion and Future Research}

Online misogyny is a form of information warfare that the United States military must take more seriously. As demonstrated in this article, there are both external and internal risks posed by the unchecked presence of online misogyny. Security sector reform that adopts a holistic gendered perspective is one way to address this threat. There are two additional potential solutions that the authors' work can help inform: the role of private companies and the viability of an ecological approach to fighting online misogyny.

The focus of this article has been to identify the existence and severity of the security threat posed by online misogyny. Yet, cybersecurity is the responsibility of organizations beyond the military. Most social media platforms are privately 
owned and have a broad transnational presence. This raises questions about the responsibility of the organizations that administer online platforms to monitor activities that occur on them and who is able to enforce rules and regulations that may apply to them. Section 230 of the Communications Decency Act of 1996 has shielded technology companies from lawsuits and responsibility for content published on their platforms. However, Twitter's decision to permanently suspend former President Trump's account has opened new discussions on how tech companies should proactively engage with potentially dangerous speech. A report from the U.S. Department of Justice argues that Section 230 should be revised to "reflect the realities of the modern digital age," including online gendered abuse, doxing, and encouraging political violence. ${ }^{99}$ This article emphasizes the need to ensure that both implicit and explicit bias in tech is studied in more meaningful ways. As we have shown, online misogyny has been historically overlooked as a security threat. There is need for more research into how this historic omission has shaped bias in automated threat identification and what aspects may have fallen through the cracks.

While the online environment has created the platform used to springboard online misogyny into physical security threats, technology solutions alone will not solve the problem. An ecological approach addresses all potential factors - social, economic, environmental, health (both physical and mental), and structural - that contribute to the security threat posed by online misogyny. Rather than addressing the consequences of online misogyny, a prevention strategy based on addressing needed social, medical, or educational services aims to address root causes. ${ }^{100}$ However, additional research is needed to determine what factors are necessary to inform an ecological approach to specifically address online misogyny. Many actions and beliefs that could potentially be included in the misogynistic panoply are deeply embedded into our public institutions. ${ }^{101}$ Interdisciplinary work in psychology, sociology, security studies, and public health is needed to determine the factors most frequently associated with individuals susceptible to engaging in the types of misogyny that result in security threats and create meaningful diversion programs. Online misogyny should not be dismissed as an overreaction on the part of feminists or diminished to simply disliking women. It presents a real security threat that has multifaceted consequences. It is neither merely boys behaving poorly on the internet, nor are its impacts only on women. Taking a gendered approach to security is a necessary first step in addressing some of the most harmful aspects of online misogyny, but there remains significant work to be done as well. As a new topic, combating this form of information warfare will benefit from research in the technological sectors, as well as multidisciplinary research to address the drivers of misogyny. 


\section{Endnotes}

1. Stuart A. Thompson and Charlie Warzel, "They Used to Post Selfies. Now They Are Trying to Overthrow the Election," New York Times, 14 January 2021.

2. Cynthia Enloe, Bananas, Beaches and Bases: Making Feminist Sense of International Politics, 2d ed. (Berkeley: University of California Press, 2014), 1.

3. Alice Marwick and Rebecca Lewis, Media Manipulation and Disinformation Online (New York: Data \& Society Research Institute, 2017).

4. Debbie Ging and Eugenia Siapera, "Special Issue on Online Misogyny," Feminist Media Studies 18, no. 4 (2018): 515-24, https://doi.org/10.1080/14680777.2018.1447 345.

5. Danielle Keats Citron, "Cyber Civil Rights," Boston University Law Review 89, no. 61 (2009): 61.

6. Enloe, Bananas, Bases and Beaches.

7. Bradley C. Nindl et al., "Operational Physical Performance and Fitness in Military Women: Physiological, Musculoskeletal Injury, and Optimized Physical Training Considerations for Successfully Integrating Women into Combat-centric Military Occupations," Military Medicine, no. 181 (2016): 50-62, https://doi.org/10.7205/MILMED -D-15-00382; and Corey Yung, "How to Lie with Rape Statistics: America’s Hidden Rape Crisis," Iowa Law Review 99, no. 1197 (2014): 1197-1256.

8. Synne Laastad Dyvik, "Women as 'Practitioners' and 'Targets': Gender and Counterinsurgency in Afghanistan," International Feminist Journal of Politics 16, no. 3 (2014): 410-29, https://doi.org/10.1080/14616742.2013.779139.

9. Valerie M. Hudson et al., Sex and World Peace (New York: Columbia University Press, 2012).

10. The manosphere is the term given to those online spaces where anti-feminist propaganda is spread. For a discussion on the manosphere, see Debbie Ging, "Alphas, Betas, and Incels: Theorizing the Masculinities of the Manosphere," Men and Masculinities 22, no. 4 (2019): 63857, https://doi.org/10.1177/1097184X17706401.

11. Christopher Whyte, "Protectors without Prerogative: The Challenge of Military Defense against Information Warfare," Journal of Advanced Military Studies 11, no. 1 (Spring 2020), https://doi.org/10.21140/mcuj.2020110108; and Mariarosaria Taddeo, "Information Warfare: A Philosophical Perspective," Philosophy \& Technology 25 (2011): 105-20, https://doi.org/10.1007/s13347-011-0040-9.

12. A most different research design is a quasi-experimental design that compares cases that are maximally different on all but the variable of interest. For a detailed discussion on the practice and applicability of most different designs, see Carsten Anckar, "On the Applicability of the Most Similar Systems Design and the Most Different Systems Design in Comparative Research," International Journal of Social Research Methodology 11, no. 5 (2008): 389-401, https://doi.org /10.1080/13645570701401552. The term incel refers to a member of an online community of young men who consider themselves unable to attract women sexually, and they are typically associated with views that are hostile toward women and men who are sexually active.

13. Kate Manne, Down Girl: The Logic of Misogyny (New York: Oxford University Press, 2017).

14. Michael A. Messner, Politics of Masculinities: Men in Movements (Thousand Oaks, CA: Sage Publications, 1997), 9.

15. Ging, "Alphas, Betas, and Incels."

16. Peter Glick and Susan T. Fiske, "An Ambivalent Alliance: Hostile and Benevolent Sexism as Complementary Justifications for Gender Inequality," American Psychologist 56, no. 2 (February 2001): 109, https://doi.org/10.1017/CBO9781139022736.005; Małgorzata Mikołajczak and Janina Pietrzak, "Ambivalent Sexism and Religion: Connected through Values," Sex Roles 70, nos. 9-10 (2014): 387-99, https://doi.org /10.1007/s11199-014-0379-3; and Miguel Moya et al., "It's for Your Own Good: Benevolent Sexism and Women's Reactions to Protectively Justified Restrictions," 
Personality and Social Psychology Bulletin 33, no. 10 (2007): 1421-34, https://doi.org /10.1177/0146167207304790.

17. Cliff Cheng, "Marginalized Masculinities and Hegemonic Masculinity: An Introduction," Journal of Men's Studies 7, no. 3 (1999): 295-315, https://doi.org/10.3149/jms .0703.295; James W. Messerschmidt, Hegemonic Masculinity: Formulation, Reformulation, and Amplification (Lanham, MD: Rowman \& Littlefield, 2018); and Yvonne Hirdman, "State Policy and Gender Contracts: The Swedish Experience," in Women, Work and the Family in Europe, ed. Eileen Drew, Ruth Emerek, and Evelyn Mahon (London: Routledge, 1998).

18. Susan Moller Okin, "Gender Inequality and Cultural Differences," Political Theory 22, no. 1 (1994): 5-24, https://doi.org/10.1177/0090591794022001002.

19. Ruth Roach Pierson, "Beautiful Soul or Just Warrior: Gender and War," Gender \& History 1, no. 1 (March 1989): 77-86, https://doi.org/10.1111/j.1468-0424.1989.tb 00237.x.

20. M. Christina Santana et al., "Masculine Gender Roles Associated with Increased Sexual Risk and Intimate Partner Violence Perpetration among Young Adult Men," Journal of Urban Health 83, no. 4 (July 2006): 575-85, https://doi.org/10.1007/s11524-006 -9061-6.

21. Pablo Castillo Díaz and Nahla Valji, "Symbiosis of Misogyny and Violent Extremism: New Understandings and Policy Implications," Journal of International Affairs 72, no. 2 (2019): 37-56.

22. Elin Bjarnegård, Karen Brounéus, and Erik Melander, "Honor and Political Violence: Micro-Level Findings from a Survey in Thailand," Journal of Peace Research 54, no. 6 (November 2017): 748-61, https://doi.org/10.1177/0022343317711241.

23. Joshua M. Roose, The New Demagogues: Religion, Masculinity and the Populist Epoch (Abingdon, UK: Routledge, 2020).

24. Joseph A. Vandello et al., "Precarious Manhood," Journal of Personality and Social Psychology 95, no. 6 (December 2008): 1325-39, https://doi.org/10.1037/a0012453.

25. Chrystie Myketiak, "Fragile Masculinity: Social Inequalities in the Narrative Frame and Discursive Construction of a Mass Shooter's Autobiography/Manifesto," Journal of the Academy of Social Sciences11, no. 4 (2016): 289-303, https://doi.org/10.1080 /21582041.2016.1213414.

26. Myketiak, "Fragile Masculinity."

27. Laura Bates, Men Who Hate Women: From Incels to Pickup Artists: The Truth about Extreme Misogyny and How It Affects Us All (New York: Simon and Schuster, 2020).

28. Ging, "Alphas, Betas, and Incels."

29. Whyte, "Protectors without Prerogative."

30. Christopher Paul and Miriam Matthews, The Russian "Firehose of Falsehood" Propaganda Model: Why It Might Work and Options to Counter It (Santa Monica, CA: Rand, 2016), https://doi.org/10.7249/PE198.

31. Oksana N. Berduygina, Tatyana N. Vladimirova, and Elena V. Chernyaeva, "Trends in the Spread of Fake News in Mass Media," Media Watch 10, no. 1 (2019): 122-32, https://doi.org/10.15655/mw/2019/v10i1/49561.

32. Soroush Vosoughi, Deb Roy, and Sinan Aral, "The Spread of True and False News Online," Science 359, no. 6380 (2018): 1146-51, https://doi.org/10.1126/science .aap9559.

33. The Pareto Principle, named after the economist Vilfredo Pareto, claims that 80 percent of consequences come from 20 percent of the causes, asserting an unequal relationship between inputs and outputs. However, this principle does not apply to sexual intercourse. CDC data show that 98 percent of women and 97 percent of men between the ages of 25-44 have had heterosexual intercourse. Anjani Chandra et al., "Sexual Behavior, Sexual Attraction, and Sexual Identity in the United States," National Health Statistics Report 3, no. 36 (March 2011): 36; and Gregory Newbold, "What Tempers the Steel of a Marine Corps Infantry Unit," War on the Rocks, September 2015.

34. John Corner, "Fake News, Post-Truth and Media-Political Change," Media, Culture 
and Society 39, no. 7 (2017): 1100-7, https://doi.org/10.1177/0163443717726743.

35. The CDC's report, based on more than 18,000 telephone survey responses in the United States, estimates that roughly 5,365,000 men had been victims of intimate partner physical violence in the previous 12 months, compared with 4,741,000 women. However, the general assessment is that more than 1 in 3 women ( 35.6 percent) and more than 1 in 4 men (28.5 percent) in the United States have experienced rape, physical violence, and/or stalking by an intimate partner in their lifetime. The numerical difference is due to the survey sample size and is not indicative of a higher instance rate of sexual violence for men than women. For reference of how it is depicted on Incels.co, see "Scientific Blackpill," Incels.wiki, accessed 7 April 2021.

36. Ebuka Elias Igwebuike and Lily Chimuanya, "Legitimating Falsehood in Social Media: A Discourse Analysis of Political Fake News," Discourse \& Communication 15, no. 1 (2021): https://doi.org/10.1177/1750481320961659; and Maria Giovanna Sessa, "Misogyny and Misinformation: An Analysis of Gendered Disinformation During the COVID-19 Pandemic," disinfo.eu, 4 December 2020.

37. Carsten Anckar, "On the Applicability of the Most Similar Systems Design and the Most Different Systems Design in Comparative Research," International Journal of Social Research Methodology 11, no. 5 (2008): 389-401, https://doi.org/10 $.1080 / 13645570701401552$.

38. Simona Frenda et al., "Online Hate Speech against Women: Automatic Identification of Misogyny and Sexism on Twitter," Journal of Intelligent \& Fuzzy Systems 36, no. 5 (2019): 4743-52, https://doi.org/10.3233/JIFS-17 9023.

39. Office of People Analytics, "Updates on Female Recruiting Market" (PowerPoint presentation, Defense Advisory Committee on Women in the Services, September 2018); and Kyleanne Hunter, "We Need What Women Bring to the Fight," War on the Rocks, 21 September 2015.

40. Marianne W. Jørgensen and Louise J. Phillips, Discourse Analysis as Theory and Method (London: Sage Publications, 2002).

41. The full video of his interrogation was ordered to be made public by Justice Anne Molloy of the Ontario Superior Court on 27 September 2019. Nicole Brockbank, "Alek Minassian Reveals Details of Toronto Van Attack in Video of Police Interview," CBC, 27 September 2019.

42. Jennifer Hickes Lundquist, "Ethnic and Gender Satisfaction in the Military: The Effect of a Meritocratic Institution," American Sociological Review 73, no. 3 (2008): 477-96, https://doi.org/10.1177/000312240807300306; and Megan MacKenzie, Beyond the Band of Brothers: The US Military and the Myth That Women Can't Fight (Cambridge, UK: Cambridge University Press, 2015), https://doi.org/10.1017 /CBO9781107279155.

43. An Overview of Social Media Trends (Alexandria, VA: Office of People Analytics, 2020), 7.

44. Maggie Fox and Erika Edwards, "Teens Spend an 'Astounding' Nine Hours a Day in Front of Screens: Researchers," West Virginia Education Institution, accessed 12 March 2021.

45. Focus group, Defense Advisory Committee in the Services, 2015-19. For all focus groups, all identifying information - to include bases and locations- have been removed to protect anonymity.

46. Focus group, Defense Advisory Committee in the Services, 2015-19.

47. There is evidence from nonmilitary contexts showing the relationship between women's sociopolitical advancement and a resulting violent backlash. The Women's Rights After War Project led by Marie E. Berry and Milli Lake is the most extensive examination of this phenomenon. Based on research in 10 countries, it found that as women obtained political and social power, they were more likely to experience violence and social backlash by men. See Sinduja Raja, Marie E. Berry, and Milli Lake, "Women's Rights After War," FBA Research Brief (December 2020). Berry and Lake's findings echo research in the corporate sector. This research dates back to the 1990s, where the business world was looking to understand ways in which to accelerate women's growth 
in corporate America, but found that backlash at the hands of fellow employees was the most common result of success. See, for example, Ronald J. Burke and Susan Black, "Save the Males: Backlash in Organizations," Women in Corporate Management 16, no. 9 (June 1997): 61-70, https://doi.org/10.1007/978-94-011-5610-3_7.

48. Kyleanne Hunter and Jeannette Haynie, "The Marines United Scandal Should Be Seen as a National Security Threat," Foreign Policy, 13 April 2017.

49. All Marines Message 008/17, Social Media Guidance—Unofficial Internet Posts (Washington, DC: Headquarters Marine Corps, 2017).

50. Focus group, Defense Advisory Committee in the Services, 2015-19.

51. Focus group, Defense Advisory Committee in the Services, 2015-19.

52. Dave Phillips and Tim Arango, "Who Signs Up to Fight? Makeup of U.S. Recruits Shows Glaring Disparity," New York Times, 10 January 2020.

53. An Overview of Social Media Trends.

54. Army Enterprise Marketing Office, "Current Army Marketing Strategy" (PowerPoint presentation, Office of the Assistant Secretary of the Army [Manpower and Reserve Affairs] to the Defense Advisory Committee on Women in the Services, Arlington, VA, 5 December 2019).

55. Focus group, Defense Advisory Committee in the Services, 2015-19.

56. Focus group, Defense Advisory Committee in the Services, 2015-19.

57. Focus group, Defense Advisory Committee in the Services, 2015-19.

58. Focus group, Defense Advisory Committee in the Services, 2015-19.

59. Focus group, Defense Advisory Committee in the Services, 2015-19.

60. Female Active-Duty Personnel: Guidance and Plans Needed for Recruitment and Retention Efforts (Washington, DC: Government Accountability Office, 2020).

61. Leo Braudy, From Chivalry to Terrorism: War and the Changing Nature of Masculinity (New York: Alfred A. Knopf, 2003).

62. The first incel forum was created in 1997 by Alana, a bisexual woman. The Alana's Involuntary Celibacy Project (AICP) was supposed to be a platform where people could connect and discuss their loneliness. However, men and latent sexism took over the forum and transformed it into self-hatred, scapegoating, and violence.

63. Ging, "Alphas, Betas, and Incels."

64. The decentralized nature of the incel movement and the historic omission of misogyny being recognized as a hate crime makes knowing the exact number of incel-inspired attacks difficult. Based on our research, the following other prominent attacks likely fall into this category: Marc Lepine, the perpetrator of the school shooting at the École Polytechnique de Montréal on 6 December 1989; George Sodini, who shot 12 women in an aerobics class in Pittsburgh, PA, on 4 August 2009; Sheldon Russell Bentley, who killed a man in a mall supermarket in Edmonton, Alberta, on 21 July 2016; Nikolas Cruz, who killed 17 people at Marjory Stoneman Douglas High School in Parkland, FL, on 14 February 2018; and a 17-year-old (name withheld since he is a minor) who stabbed three people at a Toronto massage parlor on 24 February 2020.

65. Facebook post recovered from https://www.thestar.com/news/gta/2018/04/25/number-cited-in-cryptic-facebook-post-matches-alek-minassians-military-id-source.html.

66. Retrieved from the incels.co forum.

67. When Women Are the Enemy: The Intersection of Misogyny and White Supremacy (New York: Anti-Defamation League, 2018).

68. Retrieved from the incels.co forum at https://incels.co/threads/why-you-should-neverfeel-any-remorse-for-women.259615/.

69. "Electronically Recorded Interview of Alek Minassian by Detective Robert Thomas (3917) of the Sex Crimes Unit Polygraph Unit on Monday, April 23, 2018, at 2246 Hours."

70. "Electronically Recorded Interview of Alek Minassian by Detective Robert Thomas (3917) of the Sex Crimes Unit Polygraph Unit on Monday, April 23, 2018, at 2246 Hours."

71. Alice Martini, "Making Women Terrorists into 'Jihadi Brides': An Analysis of Media Narratives on Women Joining ISIS," Critical Studies on Terrorism 11, no. 3 (2018): 
458-77, https://doi.org/10.1080/17539153.2018.1448204; Elizabeth Pearson, "The Case of Roshonara Choudhry: Implications for Theory on Online Radicalization, ISIS Women, and the Gendered Jihad," Policy and Internet 8, no. 1 (March 2016): 5-33, https://doi.org/10.1002/poi3.101; Testimony before the House Foreign Affairs Committee, 114th Cong. (28 July 2015) (testimony of Kathleen Kuehnast, "How ISIS Exploits Children by Manipulating Gender Dynamics"); and Leah Windsor, "The Language of Radicalization: Female Internet Recruitment to Participation in ISIS Activities," Terrorism and Political Violence 32, no. 3 (January 2018): 1-33, https://doi .org/10.1080/09546553.2017.1385457.

72. Dabiq Magazine, no. 11, 44.

73. Dabiq Magazine, no. 12, 19.

74. Haroro J. Ingram, "Rallying the 'True Believers' as Hardship Purifies the Ranks," Al-Rumiyah, no. 2 (October 2016).

75. Michael Kimmel, Healing from Hate How Young Men Get Into- and Out of -Violent Extremism (Oakland: University of California Press, 2019).

76. Operation Inherent Resolve: Lead Inspector General Report to the United States Congress (Washington, DC: Department of Defense, 2020), 18.

77. Operation Inherent Resolve, 19.

78. Kyleanne Hunter, "In Iraq We Were Never Neutral," Journal of Veteran Studies (forthcoming 2021).

79. Maj Ginger E. Beals, "Women Marines in Counterinsurgency Operations: Lioness and Female Engagement Teams" (master's thesis, Marine Corps Command and Staff College, 2010).

80. Nicole A. Cooke, Fake News and Alternative Facts: Information Literacy in a Post-Truth Era (Chicago, IL: American Library Association, 2018).

81. Office of People Analytics, "Updates on Female Recruiting Market."

82. Office of People Analytics, "Updates on Female Recruiting Market."

83. "DACOWITS Quarterly Business Meeting" (PowerPoint presentation, Arlington, VA, 5 December 2019).

84. Women, Peace, and Security: Strategic Framework and Implementation Plan (Washington, DC: Department of Defense, 2020).

85. Women, Peace, and Security, 12.

86. Jared Keller, "This Is a Real Slide from an Air Force Brief on the Real Threat of Incels," Task \& Purpose, 20 June 2019.

87. Jim Garamone, "Austin Orders Military Stand Down to Address Challenges of Extremism in the Ranks," Department of Defense, 3 February 2021.

88. An analysis by NPR found that 20 percent of those charged in the aftermath of the insurrection were serving or had served in the military.

89. "Landmark Resolution on Women, Peace and Security," OSAGI, accessed 24 March 2021. UN Security Council Resolution 1325, passed October 2000, was the first formal Security Council resolution to recognize the role that women play in international peace and security, and to call for an increase of women in the security sector.

90. Kyleanne Hunter and Rebecca Best, "You Can't Have Women in Peace without Women in Conflict and Security," Georgetown Security Studies Review 8, no. 2 (November 2020): 5-18.

91. Emerald M. Archer, "The Power of Gendered Stereotypes in the US Marine Corps," Armed Forces \& Society 39, no. 2 (2013): 359-91, https://doi.org/10.1177 10095327X12446924; and Kyleanne Hunter, "Of Methodology and Men," Political Violence at a Glance, 6 October 2015.

92. Kyleanne Hunter, Jeannette Haynie, and Natalie Trogus, "A Cornerstone of Peace: Women in Afghanistan," Warroom, 8 January 2021.

93. Kate McGraw, "Gender Differences among Military Combatants: Does Social Support, Ostracism, and Pain Perception Influence Psychological Health?," Military Medicine, no. 181 (2016): 80-85, https://doi.org/10.7205/MILMED-D-15-00254.

94. Nindl et al., "Operational Physical Performance and Fitness in Military Women," $50-62$. 
95. Most notably, the importance of women is highlighted in both the Army and Marine Corps counterinsurgency manuals (Counterinsurgency, Field Manual 3-24, and Insurgencies and Countering Insurgencies, Marine Corps Warfighting Publication 3-33.5, respectively). Mahlet Abera Techan, "Gendering Cyber Warfare: A Theoretical and Exploratory Paper Addressing the Research Gap on the Gendered Aspects of Cyber Warfare" (PhD diss., Upsalla University, 2020).

96. Humera Khan, "Why Countering Extremism Fails: Washington's Top-Down Approach to Prevention Is Flawed," Foreign Affairs, 18 February 2015.

97. Hudson, Sex and World Peace.

98. Cooke, Fake News and Alternative Facts.

99. Section 230-Nurturing Innovation or Fostering Unaccountability? (Washington, DC: Department of Justice, 2020). The term doxing refers to publicly revealing private personal information about a person or company.

100. An example of a successful program on which these interventions are based can be found at Stevan M. Weine and Heidi Ellis, "Mobilizing Mental Health Resources Offers Hope to Countering Violent Extremism," MDedge, 25 February 2015.

101. Hunter and Best, "You Can't Have Women in Peace without Women in Conflict and Security." 